\title{
REVIEW
}

\section{Broadening the focus of bat conservation and research in the USA for the 21st century}

\author{
Theodore J. Weller ${ }^{1, *}$, Paul M. Cryan ${ }^{2}$, Thomas J. O'Shea ${ }^{2}$ \\ ${ }^{1}$ USDA Forest Service, Pacific Southwest Research Station, 1700 Bayview Drive, Arcata, California 95521, USA \\ ${ }^{2}$ U.S. Geological Survey, Fort Collins Science Center, 2150 Centre Ave., Bldg. C, Fort Collins, Colorado 80526, USA
}

\begin{abstract}
Appropriately, bat conservation in the USA during the 20th century focused on species that tend to aggregate in large numbers and locations (e.g. maternity roosts, hibernacula) where populations are most vulnerable. Extensive research into habitat needs (primarily for roosting) of reproductive females during the previous 2 decades has produced a wealth of information useful for developing conservation strategies for this group in their summer roost areas. However, the ecological needs of males, non-reproductive females, and juveniles have received far less attention, as have the ecological needs of all bats outside the pup-rearing season. Hence, it is unlikely that a single paradigm could comprehensively address conservation needs of all demographic groups within a species because they may have different seasonal distributions, reproductive strategies, and thermoregulatory needs. Herein, we recommend research into a wider spectrum of demographic groups and seasons to form a more holistic vision of the conservation needs of bats. We urge greater attention to understanding thermo-energetic and reproductive underpinnings of observed patterns of seasonal distribution and habitat selection by bats in the USA. Such understanding is instrumental for development of scientifically sound conservation strategies to confront emerging threats to conservation of bats in the 21st century: climate change, disease, habitat degradation, and environmental contaminants. We discuss interconnections among these emerging threats and the fundamental need to incorporate understanding of thermo-energetic strategies of bats in development of conservation strategies or legislation to mitigate potential impacts on bat populations of the USA.
\end{abstract}

KEY WORDS: Bats ' Climate change ' Demographics ' Disease ' Sexual segregation · Thermoregulation · Torpor

Resale or republication not permitted without written consent of the publisher

\section{INTRODUCTION}

Challenges associated with conservation of most bats in the USA center on ensuring that strategies they have evolved for survival in highly seasonal environments are not destabilized by human actions. The crisis-driven nature of conservation biology dictates that the most obvious and pressing threats be addressed before attention is shifted from acute issues to those that may be more chronic, if no less important (Soulé 1985). Although bat conservation efforts in the USA pre-date establishment of conservation biology as a discipline, they generally conformed to this approach. Observed declines in the number of individuals occu- pying well-known hibernacula and roosts during the middle of the 20th century resulted in efforts to better monitor their numbers and establish protection measures to prevent further decline (Bogan et al. 1996, Pierson 1998). Beginning in 1967 and continuing through 1979, concern for 4 bat species or subspecies (Myotis grisescens, M. sodalis, Corynorhinus townsendii ingens, and C. $t$. virginianus) led to their listing under the US Endangered Species Act of 1973 (ESA) or its precursors (the Endangered Species Preservation Act of 1966 and the Endangered Species Conservation Act of 1969). This was followed up in 1988 by listing 2 species of nectar-feeding bats in the southwestern USA (Leptonycteris nivalis and $L$. 
yerbabuenae), when apparent declines were noted at their summer roosts. Regular monitoring of colonies and direct conservation measures, such as installation of cave gates to prevent disturbance, have provided additional protection for these species and further population-level declines in many areas appear to have been forestalled (Bogan et al. 1996, Ellison et al. 2003). Hence, relative to many other areas of the world, bat conservation in the USA appears to be on a solid footing, because the most pressing threats have been identified and strategies are in place to help conserve populations of bats considered endangered.

This should not imply that all bat populations in the USA are secure, only that, relative to other areas of the world, biologists in the USA are now in a position to look beyond the most obvious perils. Bats are confronted with a myriad of more insidious threats that are more difficult to ascertain, yet are, potentially, just as threatening to their populations. Herein, we suggest future directions for bat research that may help inform conservation efforts in the USA during the early part of the 21st century. We focus on species, habitats, and issues specific to the USA; however, we hope that many of our ideas will have relevance in other areas of the world, where progress has already been made towards addressing the most basic conservation needs of bats. We begin by recognizing biases in existing research and conservation efforts in the USA in terms of species and demographic groups previously considered and the types of threats they face. We note the great extent to which life history, ecology, and behavior of bats in the USA is shaped by the need to deal with highly seasonal environments, yet how little we know about the strategies most bats use to meet these challenges. We call for further research into a wider range of demographic groups, seasons, and situations and greater consideration of thermo-energetic underpinnings of observed behavior and habitat selection. Such considerations are critical for understanding how bats may respond to a variety of climate change scenarios and evaluating conservation options. We discuss the conservation implications of disease and modern environmental contaminants, their interrelation with thermo-energetic strategies employed by bats, and how climate change could influence these dynamics. We close with an appeal to consider expansion of legal protection measures in the USA for bats that exhibit behaviors that leave them particularly vulnerable to 21 st century threats.

\section{FOCAL VERSUS DIFFUSE THREATS}

The perils bat populations face can be divided into 2 broad categories: focal threats and diffuse threats (Table 1). Focal threats generally involve disruption of conspicuous groups of bats where impacts are relatively easy to observe either in the form of direct mortality or by dramatic changes in local abundance or condition of individuals. As such, focal threats are more likely to elicit conservation actions because both the impacts from the threat and effects of such actions are relatively easy to observe (Table 1). Diffuse threats, such as habitat loss and climate change, exposure to environmental contaminants, and disease, are generally dispersed over space and/or time and usually do not result in readily observable mortality events. As a result, diffuse threats are less likely to inspire conservation actions.

Bats that concentrate their populations at just a few sites undoubtedly represent the greatest conservation risk, because disturbance of a single site can have disproportionately large impacts on the population as a whole. Accordingly, this has been a major aspect of current protection measures afforded to bats listed under the ESA. However, diffuse threats could also have tremendous impacts on bat populations, but they are difficult to observe, quantify, and combat. For example, urbanization and deforestation are frequently cited among the most important threats to bat populations (Pierson 1998, Hutson et al. 2001, Racey \& Entwistle 2003), but the magnitudes of such effects are not amenable to direct quantification (but see Duchamp \& Swihart 2008). Nevertheless, there is little doubt that such factors negatively impact many species. Diffuse

Table 1. Categories of threats to bat populations

\begin{tabular}{|c|c|}
\hline Focal threats & Diffuse threats \\
\hline $\begin{array}{l}\text { Disruption of large maternity } \\
\text { colonies }\end{array}$ & $\begin{array}{l}\text { Loss of habitat: } \\
\cdot \text { - Forest change } \\
\text { - Agricultural land conversion }\end{array}$ \\
\hline Disruption of large hibernacula & $\begin{array}{l}\cdot \text { Fire } \\
\cdot \text { Energy development }\end{array}$ \\
\hline $\begin{array}{l}\text { Impacts to bats in roosts due } \\
\text { to contaminants or disease }\end{array}$ & $\begin{array}{l}\text { - Urbanization } \\
\text { - Climate change } \\
\text { - Water distribution/quality } \\
\text { Contaminants: } \\
\text { - Modern pesticides impacting bats away } \\
\text { from roosts } \\
\text { - Air pollution } \\
\text { - Water pollution } \\
\text { - Impacts on bat food supplies and } \\
\text { habitat structure } \\
\text { Disease: } \\
\text { - Epizootics at dispersed locations } \\
\text { - Chronic low-level infections }\end{array}$ \\
\hline
\end{tabular}


threats can affect any species, from the most solitary (e.g. species of Lasiurus) to those that form the largest aggregations (e.g. Tadarida brasiliensis). Because they tend to produce chronic-level impacts to bat populations, diffuse threats are likely to receive less attention and are more likely to be viewed with skepticism by the public. In turn, government agencies may find it more difficult to make regulatory decisions, and both government and non-government organizations may find it challenging to cultivate the sense of urgency necessary to initiate conservation actions. In spite of the underappreciated importance of diffuse threats, conservation theory and common sense dictate that priority should be assigned to focal threats that are easy to define and, hopefully, easy to address. Continued vigilance toward focal threats will be necessary to maintain the gains achieved to date, but conservation attention in the 21st century must increasingly turn to defining and combating diffuse threats. This will mean engaging in issues that historically have received little attention. Examples of such challenges include documenting the effects of habitat destruction, climate change, newer classes of insecticides, disease, and the interactions of these factors on bat populations.

\section{CONSPICUOUS VERSUS INCONSPICUOUS SPECIES}

Addressing conservation concerns for the large proportion of species that are rarely imperiled by focal threats, because they do not form large aggregations, will be a further conservation challenge during the 21st century. Similar to the threats that face bat populations, species of bats in the USA can be grouped according to their propensity to aggregate conspicuously (Table 2). We define conspicuous species as those that tend to roost or hibernate in structures where they are relatively easy for humans to observe (e.g. caves, mines, buildings) and sometimes form large aggregations in these structures. Conspicuous species also include those that, although they do not necessarily form large aggregations, are difficult to detect (e.g. via capture or detection of their echolocation calls) except when in their roosts or hibernacula (e.g. Corynorhinus spp.). Inconspicuous species are those that tend to roost in small groups in places difficult for humans to observe or access - such as foliage or cavities in trees or crevices in rocks. Inconspicuous species sometimes roost or hibernate in caves, mines, or buildings (e.g. Myotis leibii) and some occasionally form large aggregations (e.g. Myotis thysanodes in Carlsbad Caverns; Baker 1962). Nevertheless, we categorized these species as inconspicuous because roost groups are infrequently encountered or observed by humans. Conversely, a few conspicuous species that form aggregations in caves (e.g. Tadarida brasiliensis) or buildings (e.g. Eptesicus fuscus) can also roost inconspicuously in rock crevices or trees.

In terms of legal protection measures conferred by the ESA, there is a strong bias toward conspicuous species of bats (Table 2). As noted above, species which concentrate large segments of their population at just a few sites are inherently more vulnerable than those that form smaller groups in a greater number of locations; therefore, conservation of aggregating species

Table 2. A total of 45 bat species from the USA categorized according to their roosting habits.

\begin{tabular}{|c|c|c|}
\hline Conspicuous species & \multicolumn{2}{|l|}{ Inconspicuous species } \\
\hline Choeronycteris mexicana & Antrozous pallidus & Myotis auriculus \\
\hline Corynorhinus rafinesquii & Artibeus jamaicensis & Myotis californicus \\
\hline Corynorhinus townsendii ${ }^{\mathrm{a}, \mathrm{b}}$ & Euderma maculatum & Myotis ciliolabrum \\
\hline Eptesicus fuscus & Eumops floridanus & Myotis evotis \\
\hline Leptonycteris yerbabuenae & Eumops perotis & Myotis keenii \\
\hline Leptonycteris nivalis ${ }^{\mathrm{a}}$ & Eumops underwoodi & Myotis septentrionalis \\
\hline Macrotus californicus & Idionycteris phyllotis & Myotis thysanodes \\
\hline Mormoops megalophylla & Lasionycteris noctivagans & Myotis volans \\
\hline Myotis austroriparius & Lasiurus blossevillii & Myotis yumanensis \\
\hline Myotis grisescens ${ }^{\mathrm{a}}$ & Lasiurus borealis & Myotis leibii \\
\hline Myotis lucifugus & Lasiurus cinereus $^{\mathrm{a}, \mathrm{c}}$ & Nyctinomops femorosaccus \\
\hline Myotis sodalis & Lasiurus ega & Nyctinomops macrotis \\
\hline Myotis velifer & Lasiurus intermedius & Nycticeius humeralis \\
\hline Tadarida brasiliensis & Lasiurus seminolus & Parastrellus hesperus \\
\hline & Lasiurus xanthinus & Perimyotis subflavus \\
\hline & Molossus molossus & \\
\hline \multirow{2}{*}{\multicolumn{3}{|c|}{$\begin{array}{l}{ }^{a} \text { Species listed under the US Endangered Species Act (ESA) } \\
\text { bSubspecies Corynorhinus townsendii ingens and C. t. virqinianus listed under ESA }\end{array}$}} \\
\hline & & \\
\hline \multicolumn{3}{|c|}{ "Subspecies Lasiurus cinereus semotus is restricted to Hawaiian Islands and is listed under ESA } \\
\hline
\end{tabular}


should be a priority. Nevertheless, it is worth noting that the relative ease of observing and quantifying impacts to conspicuous species undoubtedly played a role in their recognition as endangered species. Further, conservation actions such as installation of gates at openings to large roosts tend to produce tangible results at minimal cost and cause controversy only with small and local segments of the human population. This creates a positive feedback loop in which results justify and inspire similar types of conservation work elsewhere. We reiterate our support of such conservation strategies because of the unequivocal benefits to affected populations of bats and secondary benefits that accrue for bat conservation when public attention is focused on effectual conservation actions. Nevertheless, we are concerned about the relative lack of legal conservation status attributed to a much longer list of inconspicuous species (Table 2). There are twice as many inconspicuous as conspicuous species in the USA, yet the only inconspicuous species listed under the ESA is the Hawaiian sub-species of hoary bat Lasiurus cinereus semotus. The lack of inconspicuous species recognized under the ESA may, in part, be an artifact of difficulties in defining diffuse threats and quantifying impacts to populations composed of small, dispersed groups of individuals. Indeed, prior to administrative policy changes a little over a decade ago, fully one-third of the inconspicuous species in Table 2 were officially designated as Category 2 candidates for listing under the ESA, formally defined as 'taxa for which information... indicates that proposing to list as endangered or threatened is possibly appropriate but for which persuasive data on biological vulnerability and threat are not currently available to support proposed rules' (US Fish and Wildlife Service 1994, p. 58 984). Although the US federal government no longer recognizes a Category 2 distinction (for a history in relation to bats in the USA see O'Shea et al. 2003), the need to support research and monitoring efforts that would contribute to scientifically credible policy decisions on these species has not been obviated. Recent reviews of extinction risk in bats predict species with small geographic ranges, narrow dietary breadth, and low aspect-ratio wings generally will be the most vulnerable (Jones et al. 2003, Safi \& Kerth 2004, Boyles \& Storm 2007). Such characteristics are embodied by some inconspicuous, forest-dwelling species (e.g. Myotis keenii) for which, due to limited dispersal capabilities, habitat destruction may be the greatest threat.

Although early conservation actions and policies largely focused on conspicuous species, bat research efforts over the past 2 decades have increasingly focused on forest-dwelling, inconspicuous species. Due in part to increased availability of miniature radio- transmitters, studies of roost selection by bats in forests have resulted in a rich understanding of the great extent to which bats rely on trees for roosts and have revealed strong patterns in the types of trees and surrounding habitats used by bats in the USA (Hayes 2003, Kunz \& Lumsden 2003, Barclay \& Kurta 2007, Brigham 2007). Given strong similarities in the results of these studies, it is tempting to generalize patterns of roost selection observed to date as representative for a species or even for bats as a group. However, it is important to remain mindful that the majority of these studies were conducted on reproductive females during the warm season.

\section{SEX AND AGE BIASES}

Until recently, most studies of roost and habitat use by forest-dwelling bats centered on reproductive females (Barclay \& Kurta 2007), whereas the needs of males were rarely considered. Bats rely on behavioral as well as physiological thermoregulation, and we should expect differences among demographic groups (e.g. sex, age, reproductive status) that help them meet their divergent thermoregulatory needs (Altringham \& Senior 2005, Boyles et al. 2007). Planning for the conservation of bats in the USA will undoubtedly benefit from a clearer understanding of the patterns and causes of these differences (Rubin \& Bleich 2005).

\section{Reproductive females}

Given a lack of information on so many inconspicuous, forest-dwelling species, a focus on reproductive females was appropriate because they are universally regarded as the most critical demographic group and the one for which suitable roost structures are presumed to be most limited (Humphrey 1975, Kunz \& Lumsden 2003). Reproductive females of species that roost in crevices and cavities of trees tend to use tall, large-diameter snags in early to middle stages of decay (Brigham \& Barclay 1996, Hayes 2003, KalcounisRüppell et al. 2005, Barclay \& Kurta 2007). Roost trees are often found at greater distances from other large trees, surrounded by large numbers of other snags, or in areas of lower canopy cover than other available snags (Hayes 2003, Kalcounis-Rüppell et al. 2005, Barclay \& Kurta 2007). They are often found near gaps and edges, on upper slopes, or at slope aspects that maximize solar exposure on the roost tree (e.g. Waldien et al. 2000, Cryan et al. 2001, Weller \& Zabel 2001). Although multiple hypotheses have been proposed to explain these patterns of roost selection (Hayes 2003, Barclay \& Kurta 2007), the most compelling and consis- 
tently applicable suggestion is that they represent a combination of factors that help maximize the warmth of the roost relative to other trees and structures available in the landscape.

Selection of warm roost structures, in combination with colonial behavior at maternity sites, helps reproductive females remain homeothermic during the critical phases of pregnancy and, especially, lactation (Racey 1982, Speakman \& Thomas 2003). Use of such behaviors (combined with infrequent use of torpor) during spring and summer likely facilitates fetal development, milk production, replenishment of calcium stores, and growth of young, while minimizing costs of thermoregulation (Racey 1973, Kurta 1986, Kunz \& Stern 1995). Although only a few studies have quantified roost microclimate or use of torpor by forest-dwelling bats (Genoud 1993, Cryan \& Wolf 2003, Boyles 2007, Willis \& Brigham 2007), this is a convincing line of reasoning that explains observations on roost selection in terms of what is known about thermoregulatory strategies of reproductive female bats. Further research that examines the reasons behind maternity roost selection will improve our ability to conserve suitable habitat for reproductive females (Boyles 2007). However, expansion of work to address selection of habitat by additional demographic groups (e.g. males, juveniles) is needed to address the conservation needs of bats in a more comprehensive manner.

\section{Males}

Research into roost selection by males has only recently become a subject of interest for North American bats. Of the 67 studies on individual species reviewed through 2004, only 5 considered roost use by males separately (Barclay \& Kurta 2007). Although males have begun to receive attention during the past several years (e.g. Broders \& Forbes 2004, Ford et al. 2006, Perry et al. 2007), few consistent patterns have emerged regarding the types of roosts or surrounding habitat used by male bats. Male bats are unlikely to form colonies during summer, although exceptions occur in certain species (e.g. bachelor colonies of Tadarida brasiliensis and Myotis lucifugus). Studies that have investigated male behavior during spring and summer often found them roosting alone, occupying more exposed or cooler roosts than reproductive females, and using torpor more frequently than females during both day and night (Kurta \& Fujita 1988, Barclay 1991, Hamilton \& Barclay 1994, Grinevitch et al. 1995, Cryan \& Wolf 2003, Dietz \& Kalko 2006). However, male bats are also sometimes found roosting in the same habitats and roosts as reproductive females during the summer (Kurta \& Kunz 1988, Hamilton \& Barclay 1994), indicating they employ a range of roosting strategies.

Relative to sex-specific differences in roost use, more is known about seasonal differences in distribution between males and females. Males often segregate from females during spring and early summer (Crichton \& Krutzsch 2003, Altringham \& Senior 2005). For example, in mountainous regions, reproductive female bats tend to occur at lower elevation sites than males during the maternity period (Thomas 1988, Barclay 1991, Grindal et al. 1999, Cryan et al. 2000, Senior et al. 2005, Neubaum et al. 2006), and several species of tree bats in both North America and Europe exhibit sexual segregation at continental scales (Findley \& Jones 1964, Strelkov 1969, Cryan 2003, Estók 2007). In most cases, regions occupied by reproductive females during the maternity period tend to be warmer and are presumed to have greater abundances of prey, while males tend to occur in cooler areas where prey is presumably more limited.

Why do males behave this way? Several explanations have been proposed (Barclay 1991, Hamilton \& Barclay 1994, Altringham \& Senior 2005, Encarnação et al. 2005, Senior et al. 2005). The undercurrent of reasoning in the literature has been that females somehow exclude males from prime habitats (Encarnação et al. 2005, Senior et al. 2005; we term this the 'submissive male hypothesis') or males can persist in marginal habitats because they have less stringent energy needs than reproductive females (Encarnação et al. 2005; 'low-maintenance male hypothesis'). For instance, the frequent occurrence of male bats at high elevations is sometimes interpreted as evidence for their tolerance of marginal habitats, but the notion that such habitats are of lower quality is itself rooted in the paradigm of evaluating habitat needs of bats in terms of the thermo-energetic needs of reproductive females. Alternatively, males may use torpor more often than females during summer to reduce the amount of time spent foraging in order to minimize the odds of predation (Barclay 1991, Grinevitch et al. 1995; 'cautious male hypothesis'). Segregation by males may also decrease foraging competition with pregnant and lactating females and juveniles, which may increase reproductive success of the population (Kunz et al. 1998; 'facilitating male hypothesis'). Whatever the explanation, male bats will actively seek conditions that maximize their chances of survival and successful reproduction, and it is likely that a range of male-specific survival and mating strategies exist. Under certain situations, environmental conditions which males favor may be quite unlike those sought by reproductive females during summer (Thomas 1988, Barclay 1991, Grinevitch et al. 1995). 
Sex-specific differences in behavior and habitat selection are likely to reflect differences in reproductive as well as thermoregulatory strategies employed by males and females. Female animals that provision offspring with energy gained concurrently are termed 'income breeders', whereas those that provision offspring using energy stores accumulated at an earlier time are termed 'capital breeders' (Jönsson 1997). Applying a similar concept to presumed sex differences in energy requirements by bats, female bats likely tend toward income breeding (Henry et al. 2002), whereas selection might favor a strategy of capital breeding in males. The most important periods of the reproductive cycle for females are likely those involving the pre- and post-natal development of young. Females facilitate these developmental processes by attempting to remain homeothermic via selection of warm roosts and frequent foraging bouts during pregnancy and lactation. These periods generally correspond well with seasonal peaks of prey density in North America. For males, on the other hand, the most important period of the reproductive cycle is mating, which largely occurs in cool seasons when insect prey is less abundant. Males may increase their chances of successful reproduction by engaging in behaviors (e.g. solitary roosting, torpor use) that facilitate fat storage prior to the mating and hibernation period. Males with greater energy stores going into the mating period would gain a fitness advantage over those preoccupied with feeding during autumn (Kunz et al. 1998). Such males may also be capable of more frequent arousals during hibernation, and male bats have been observed copulating with females in winter hibernating groups (McCracken \& Wilkinson 2000).

In a review of the influence of sexual segregation on conservation options, Rubin \& Bleich (2005, p. 380) challenged others to '...consider the many ways in which a particular behavioral phenomenon can influence conservation strategies.' As such, we propose that uncovering details of male thermoregulatory and reproductive strategies should be an important component of bat conservation in the future. Selection should favor males that are best able to accumulate surplus energy for later use toward mating during autumn and winter when insect prey is limited and activity requires greater metabolic expenditure. In addition to possible energetic benefits of male torpor at high-elevation sites during summer, occupancy of such areas by males might indicate year-round occupancy and defense of wintering sites that are visited by overwintering females. For example, female big brown bats Eptesicus fuscus that spend summer in maternity colonies at low-elevation sites at the edge of the Great Plains migrate up into high elevations of the adjacent Rocky Mountains to hibernate in areas where males tend to occur in greater numbers during summer (Neubaum et al. 2006). If winter roosts with suitably cold temperatures for successful hibernation are limited at higher elevations, then defense of such sites by males and visitation by females for mating (as has been posited for several European species; Zahn \& Dippel 1997, Sachteleben \& von Helversen 2006, Encarnação et al. 2007) is plausible.

In summary, we join the growing chorus of other researchers in arguing that conservation needs of males and reproductive females should be considered separately whenever possible (Broders et al. 2006, Barclay \& Kurta 2007, Safi et al. 2007). Because males and reproductive females of the same species may have different seasonal distributions, different reproductive strategies, and select roosts with differing characteristics to meet their thermoregulatory needs, it is unlikely a single paradigm will simultaneously address the conservation needs of both groups. For example, recommendations for management of forested habitat based on patterns of roost use by reproductive females during summer (e.g. tall snags in low elevation areas) would not necessarily meet the needs of males (or nonreproductive females). We have argued that males are likely to actively select habitat that allows them to fulfill their thermoregulatory and reproductive needs rather than passively accept available habitats. If achieving these goals is facilitated by roosting singly, then the number, type, and location of roosts on the landscape may differ markedly from those used by reproductive females. Currently, information required to assess the validity of such scenarios is almost completely lacking. As such, we believe that obtaining sexspecific information on the behavior and habitat needs of bats should be one of the primary goals of future conservation efforts. We acknowledge the challenges in doing so for multiple species, but contend it is the only way to achieve a holistic vision for bat conservation in the 21st century.

\section{Juveniles}

In addition to exploring differences between males and females, it will also be important to assess differences between volant juvenile and adult bats. We know much about parturition, growth, and activity of bats in their first few weeks, but very little about strategies that have evolved to increase survival probabilities after young leave maternity sites in their first year of life. Survival and reproduction in hibernating bats are contingent upon the accumulation of body mass and fat reserves during autumn (Kunz et al. 1998). Young bats might accumulate less fat than adults prior to hibernation and thus be more susceptible to energy 
deficits during winter (Kokurewicz \& Speakman 2006). As overwinter survival of first-year bats is typically lower than that of adults (O'Shea et al. 2004), it is surprising so few studies have focused on survival strategies and habitat needs of juveniles throughout their first year. Volant juveniles likely find it more difficult to add the body mass necessary for hibernation because they are still trying to perfect the flight skills necessary for effective foraging (Hamilton \& Barclay 1998). As a result, their diets may differ from those of adults both in quantity and type of prey taken (e.g. Rolseth et al. 1994). Additionally, within populations, some female bats do not reproduce in their first year of life (Barclay et al. 2004), perhaps because of a lack of fat reserves acquired during the summer of birth (Kunz et al. 1998). Because of the limited reproductive capacity of bat populations, ensuring that the habitat needs of juveniles are met may be an important step toward improving overall recruitment. Doing so will require better quantification of survival rates of juveniles in their first year (e.g. Frick et al. 2007), along with demographic modeling to determine the contribution of yearlings to population growth rates. Field research that examines juvenile-specific habitat selection, seasonal activity periods, and thermoregulatory behavior may help explain some of the ecological factors that influence survival and recruitment of juveniles. Better knowledge of juvenile ecology will help to determine whether agespecific conservation measures are necessary.

\section{SEASONAL BIASES}

Bat monitoring and research efforts have historically focused on aggregations of conspicuous species found during winter or on activities of adult females of both conspicuous and inconspicuous species during summer. Much less is known about activities of most bats during the spring and autumn, or the whereabouts of inconspicuous species during winter. This seasonal bias to our understanding of bat ecology is unfortunate, as these are periods when vital and energetically expensive activities such as breeding, migration, and hibernation occur.

In general, we know almost nothing about wintering habits of hibernating species of bats that do not use caves or mines. Even for some of those species known to hibernate in caves or mines, existence of less-conspicuous hibernation sites (too small for humans to enter) may cumulatively provide more winter habitat than caves or mines (Griffin 1945). For example, the winter habits and whereabouts of most species in western North America are not known, although they may rely on deep rock crevices or trees as wintering sites (Bogan et al. 2003, Hayes 2003, Boyles \& Robbins 2006,
Neubaum et al. 2006, Cryan \& Veilleux 2007). Furthermore, the wintering grounds and migration routes of migratory tree bats also remain largely unknown (Fleming \& Eby 2003, Cryan \& Veilleux 2007). Recent work has expanded upon the diversity of latitudes and climatic conditions where bats have been found to be active during winter (Boyles et al. 2006, Lausen \& Barclay 2006, Geluso 2007). These findings suggest that opportunities to learn more about the winter ecology of bats may not be entirely limited to lower latitudes or coastal areas. Broadening understanding of spatial and temporal patterns of winter bat activity, and its explanations (Boyles et al. 2006), will be important for improving our ability to meet the year round conservation needs of bats in the USA.

Behavior and habitat use of bats during transitional periods of spring and autumn are perhaps least known of all. During late summer and autumn, bats use altitudinal, regional, or continental-scale migrations to move between their summer and winter ranges. These seasonal movements are generally considered to be coincident with the primary period of mating for bats in the USA. Despite the obvious energetic and reproductive importance of these activities to bats, we know very little about the specifics of their movements or behaviors during autumn (and even less during spring). For many species of bats in the USA, locations where they mate remain unknown. The implications of this are profound. Lack of information on mating sites and migration routes of bats precludes our ability to safeguard them from ongoing threats to their populations (e.g. habitat loss) as well as from emerging threats such as wind energy development and climate change.

\section{CLIMATE CHANGE}

As mobile animals with a good deal of flexibility in thermoregulatory options available to them, bats may be less susceptible to thermal effects of climate change than many other organisms. Bats use physiological and behavioral thermoregulation to respond to temperature changes on a daily and seasonal basis and may therefore be pre-adapted, in a sense, to deal with this aspect of climate change. Nevertheless, because thermoregulation influences nearly every aspect of their lives (e.g. foraging strategy, roost selection), consideration of how climate change may impact the ecology and behavior of bats in the USA will undoubtedly be important for their conservation during the 21st century. The impacts of climate change on bats in the USA are difficult to characterize and will undoubtedly vary according to species, sex, season, and pattern in which global climate change is expressed in a particular geographic region. Timely and credible documentation of 
climate-induced changes in animal distributions across latitude or elevation (Wilson et al. 2005, Sekercioglu et al. 2008) will be difficult to achieve for bats in the USA because of a scarcity of inventory work in many areas, a lack of a central repository for inventory results, and a consequent poor resolution into existing patterns of distribution (O'Shea \& Bogan 2003). Such deficiencies are conceptually simple to remedy but are complicated by institutional and logistical inertia. We focus attention instead on the need to understand how climate change may impact the behavior of bats and ultimately their distribution and selection of habitat. We consider a few proposed climate change scenarios, speculate on how these may impact the ecology of affected species, and consider some of the ways that bats might cope with these changes.

\section{Impacts of warming climate during winter}

The general strategy of overwinter survival for the majority of bat species in the USA is to spend winter in sheltered sites that are sufficiently cold, humid, and free of disturbance to promote prolonged bouts of torpor (hibernation). Energetic requirements of torpor generally decrease with temperature of the hibernation site and with the number of energetically expensive arousals that occur (Humphries et al. 2002, Speakman \& Thomas 2003). Hence, one seemingly obvious impact of climate change is that warmer temperatures at wintering sites will make it more difficult for hibernating bats to conserve the fat reserves they rely on during winter when insect prey is not available (Humphries et al. 2002). As a result, it has been predicted that the distribution of hibernacula suitable to overwintering bats may shift to higher latitudes and elevations (Humphries et al. 2002). An important assumption in this scenario is that structures used as hibernation sites (e.g. caves, mines, and rock crevices) will be equally available at higher latitudes and elevations. This assumption may not be wholly adequate, particularly in karst-free regions of higher latitudes and near tops of mountains where there is little room for upward expansion. Many populations of endangered species of bats that hibernate in the USA do so in karst regions, which will not shift as the climate changes. The apparent 'trial-and-error system' (sensu Twente 1955) of behavioral thermoregulation in hibernating bats suggests that a need to find new and suitable wintering sites could lead to negative population impacts, at least over the short term (i.e. several generations). This may be particularly noticeable in regions of the eastern USA where several species expend considerable energy migrating from summer habitats to suitable hibernacula.
Rather than seeking alternate hibernacula, bats may respond to warmer winter temperatures by reducing depth or total duration of torpor during winter. Although this would result in higher rates of depletion in stored energy on a daily or weekly basis, it may be countered by shorter winter lengths, greater periods of prey availability in some areas, and avoidance of some of the negative consequences of long-term torpor use (Humphries et al. 2003, Wojciechowski et al. 2007). This suggests that it may not be advantageous for all bats to attempt to maximize torpor use during hibernation via selection of thermally stable, cold, and humid environments (Humphries et al. 2003, Boyles et al. 2007, Wojciechowski et al. 2007). Further research that explores the range of thermoregulatory behaviors used by bats - in relation to temperature and humidity conditions experienced in winter hibernacula - is needed before credible strategies to protect hibernating bats from detrimental impacts of climate change can be developed.

\section{Impacts of greater climate extremes}

Decreases in the predictability of seasonal climate patterns hold a potential to disrupt the timing of thermo-energetic and reproductive activities of bats and may present a further threat to bat populations. In addition to a general warming trend, regional climate change scenarios predict greater extremes in variability of weather events such as droughts and floods, more severe storms, and an increase in the number of hot spells (Christensen et al. 2007). Delayed or decreased reproduction in some species of bats has been attributed to both unusually wet or dry conditions (Racey 1973, Ransome 1990, Grindal et al. 1992, Rhodes 2007), cold snaps in autumn have killed large numbers of little brown bats thought to be in migration (Zimmerman 1937), and flood events at caves associated with spring and summer storms have killed thousands of bats of several species in the USA, including species now considered to be endangered (DeBlase et al. 1965, Gore \& Hovis 1994). Hence, extreme climate events can have directly negative consequences for bat populations.

Greater climate variability also has the potential to impact thermo-energetic and reproductive strategies of bats in the USA in less obvious ways. Early onset of cold conditions during autumn or extension of cold, wet conditions into the spring will influence overwinter survival and subsequent reproduction of hibernating bats, especially for smaller species that have less flexibility in energy storage and torpor use over winter (Grindal et al. 1992, Boyles et al. 2007). Climate change may also produce subtle changes in the sea- 
sonal timing of important annual events such as mating and migration. Documenting or predicting disruption of mating events will be challenging because the timing and location of such activities are poorly understood. Swarming sites provide important locations where males and females (which may be widely separated during summer) come together for mating during autumn and may therefore be critical for maintenance of genetic diversity in populations (Furmankiewicz \& Altringham 2007). In the eastern USA, swarming sites are often located at entrances to caves and mines. Improved monitoring of the timing and intensity of swarming behavior at such sites may be an important first step toward documenting possible changes in reproductive behavior associated with climate change. Locations of swarming sites and timing of swarming events in the western USA are poorly known, but there is increasing speculation that inconspicuous species may have seasonal rendezvous sites (e.g. at trees or rock outcroppings) that play a role in mating behavior (Neubaum et al. 2006, Cryan 2008). If climate change alters the timing of seasonal cues in ways that disrupt patterns of arrival by males and females at such sites, there could be negative consequences for reproduction. The probability of asynchrony at mating sites would be greater for species that segregate by sex during summer and are thus exposed to a different set of environmental cues (e.g. temperatures or extreme weather events) that may trigger migration and mating behavior. Similarly, species that rely on a predictable supply of food along migration routes or at their migration endpoints are vulnerable to asynchrony with phenologies of their prey caused by changes in local climate (e.g. Both et al. 2006). Extremes and variability in other factors associated with climate change and its effects on biotic communities (including precipitation patterns, hydrological cycles, frequency and severity of fires) may also impact bats and their prey in complex ways that are beyond the scope of this paper to review in detail.

\section{Impacts of warming climate during summer}

Impacts of warmer summers on bats in the USA may differ markedly between males and females. Warmer and longer summers could result in earlier parturition in some areas (Grindal et al. 1992), faster growth of pups (Racey 1973, Kurta 1986, Kunz \& Stern 1995), and longer periods during which reproductive females and juveniles could feed before winter (Bale et al. 2002), thereby resulting in positive effects on both reproduction and survival in bat populations. However, males, which likely make greater use of torpor throughout the year (see 'Sex and age biases'; 'Males' above), could face fewer options with warmer climate. In mountainous areas, there are likely to be reductions in thermal gradients across elevation and therefore fewer advantages to be gained from selection of cooler, high-elevation sites that facilitate torpor use by males. In regions with less topographic relief, the thermal benefits of selecting cooler roosts (e.g. small trees beneath the canopy) may also be diminished, and bouts of torpor may thereby become less frequent or shallower. Thus, any selective advantage conferred on males that maximizes use of torpor during summer could be compromised by warmer temperatures. This raises the specter that, regardless of whether distributions or persistence of species are impacted, climate change may alter the prevalence of thermoregulatory and reproductive strategies that have evolved over millennia. Ultimately, such behavioral changes may manifest themselves in population-level impacts. Better understanding of the prevalence and flexibility of the thermoregulatory strategies employed by male bats will improve our ability to predict their response to climate change.

Warming climate also may influence roosting dynamics of reproductive females during summer. Hotter daytime temperatures have been associated with roost-switching by female big brown bats Eptesicus fuscus during the maternity season (Ellison et al. 2007). Roost-switching by these bats was most common on the hottest days (Ellison et al. 2007) and is likely to become more common, as increased frequency of heat waves is one of the most likely outcomes of climate change, particularly in the western USA (Christensen et al. 2007). Increased energy expenditure and risk of accidents or predation associated with roost-switching during pup-rearing could decrease reproductive success. In addition, Ellison et al. (2007) speculated that frequent roost-switching among buildings could lead to increased contact with humans, which, as public concerns regarding bats as nuisances or health risks increase (see 'Diseases' below), would result in negative consequences for bat conservation.

\section{DISEASES}

Other than rabies, diseases in bat populations were not considered a major human health concern or a significant threat to conservation of bats in the USA during the 20th century. However, until recent years, proportionally few researchers focused their attention on disease in bats, and those that did mostly worked on the rabies virus (Messenger et al. 2003). Recent increases in attention from virologists to bats and their diseases, both globally and in the USA (Calisher et al. 
2006, Dominguez et al. 2007), and accompanying publicity in the popular media promise to present challenges for bat conservation during the 21st century.

\section{Rabies}

In the USA, rabies is the primary disease associated with bats. Following its discovery in a yellow bat, Lasiurus intermedius, in Florida during the early 1950s (Scatterday 1954), significant research was initiated on the occurrence of rabies in bats in the USA, most of which was conducted in the late 1950s and 1960s. Thereafter, state and local health agencies initiated programs to examine the brains of bats encountered by the public for evidence of rabies infection. Entrusted with and motivated by the health of the public, these agencies also began education programs aimed at preventing exposure of citizens to rabid bats. Inappropriate and misguided reactions sometimes led to direct killing of bats at roosts by individuals who felt justified by fears of rabies. In part because of continued vigilance by public health agencies (>93000 bats were submitted for rabies testing in the USA from 1993 to 2000; Mondul et al. 2003), human deaths associated with bat rabies have been infrequent in the USA (currently 0 to $5 \mathrm{yr}^{-1}$; De Serres et al. 2008). This has resulted in human health concerns associated with bat rabies being downplayed in conservation efforts. Bat researchers and conservationists have tended to counteract negative attention from rabies cases by comparing bat rabies to other very rare forms of human mortality (e.g. lightning strikes).

Epizootic diseases (those that ravage populations and quickly lead to high levels of mortality, i.e. dieoffs) have not been documented in bats in the USA (Messenger et al. 2003). This is true for rabies, and the presence of rabies-neutralizing antibodies in the blood of healthy bats suggests that bats are more capable of surviving exposure to this disease than are other mammals (e.g. Shankar et al. 2004, Pearce et al. 2007). The lack of obvious die-offs due to rabies or other diseases in bats has the potential to give some researchers the false impression that infectious disease is a relatively unimportant source of mortality in bats. The more likely truth is that beyond rabies investigations, there has simply been very little research into the occurrence and effects of other diseases in bats in the USA during the 20th century.

\section{Emerging infectious diseases}

Recently though, bats have captured the attention of virologists interested in documenting reservoirs of dis- ease in wild animals and controlling their spread to humans (e.g. Dobson 2005, Calisher et al. 2006). The list of diseases, recently identified as emerging from bats, that have spilled over into humans worldwide includes some with serious consequences that have the potential to terrify the public, including Ebola, Sudden Acute Respiratory Syndrome (SARS), Marburg, Hendra, and Nipah viruses (Table 3). Calisher et al. (2006) listed 66 viruses known from bats around the world based on literature appearing from 1925 through 2005. This is probably a small fraction of the likely number of bat viruses globally, given ca. 1100 species of bats (Simmons 2005) and little past attention to their diseases. Numerically, bats are not overrepresented among mammals as reservoirs of pathogens that emerge in humans (Dobson 2005). However, because of their association with high profile diseases that are deadly to humans, bats have been the subject of increasing scrutiny by virologists. Between January 2006 and April 2008, at least 7 additional viruses have been identified in bats (Calisher et al. 2008), attesting to the rapid growth of interest by virologists to diseases in bats. Reports of these studies in the popular media, regardless of the country in which they were conducted, complicate efforts to cultivate positive images of bats that could aid conservation efforts in the USA and around the world.

It is becoming increasingly apparent that viral diseases show unique dynamics in bats (Calisher et al. 2006). Distinctive aspects of the ecology and life histories of bats make them particularly likely to serve as origins for emerging viruses (Dobson 2005, Calisher et al. 2006), particularly the RNA viruses that have a high capacity for mutation and host-jumping (Childs et al. 2007). Bats are long-lived, which facilitates viral persistence; some species migrate over long distances, which can promote transport of infectious agents; and many species live in dense aggregations, which can facilitate rapid transmission of viruses (Calisher et al. 2006). Additionally, some species roost commensally with humans in buildings, and anthropogenic habitat encroachment is suspected of facilitating spill-over of pathogens from bats to humans and domestic animals in other parts of the world (Dobson 2005, Calisher et al.

Table 3. Viral diseases, recently identified as emerging from bats, that have spilled over and produced mortality in human populations. SARS: Sudden Acute Respiratory Syndrome

\begin{tabular}{|lll|}
\hline Disease & Location & \multicolumn{1}{c|}{ Source } \\
\hline Ebola & Africa & Leroy et al. (2005) \\
Hendra & Australia & Halpin et al. (2000) \\
Marburg & Africa & Towner et al. (2007) \\
Nipah & Asia & Reynes et al. (2005) \\
SARS & Asia & Janies et al. (2008) \\
\hline
\end{tabular}


2006, Wong et al. 2007). Mounting evidence that these diseases come from bats has generated great interest from infectious disease researchers and public health officials (e.g. Dobson 2005). The number of papers published on bats and disease has increased dramatically in the past few years and much of this work is being done by virologists with little experience in bat ecology. This has sometimes caused uneasy tension between virologists, bat ecologists, and conservationists (Fenton et al. 2006). The fear by conservationists is that negative attention or misinterpretation associated with disease discovery will impair bat conservation efforts worldwide. As a result, reports of disease in bats have sometimes been dismissed or met with an adversarial tone by bat conservationists; and there are few examples of collaboration between virologists and bat ecologists. An undeclared strategy of bat conservationists seems to have been to minimize the potential importance of disease in bats, because acknowledging its importance might undermine conservation efforts. We argue this strategy is untenable and may be counterproductive to the conservation of bats in the USA. A failure by bat researchers to acknowledge and address the occurrence of disease in bat populations could have many unintended consequences. The capacity of many bats to harbor viral infections without mass mortality may indicate their life histories have resulted in unique selective forces and biological mechanisms that allow them to thwart some disease organisms (Calisher et al. 2006). It is conceivable that lessons can be learned from bats at physiological and molecular levels that will lead to insights beneficial to human medicine (Dobson 2005), and this possibility is one that both bat biologists and public health advocates should agree provides additional justification for bat conservation.

\section{Effects of anthropogenic change on disease dynamics}

Anthropogenic changes in climate and landscape use and widespread occurrence of immunosuppressive chemical contaminants have the potential to alter disease cycles in bats, as well as increase the probability of disease spill-over from bats to humans and other animals. The Nipah virus, for example, spilled over into humans in Malaysia, largely because of encroachment into bat habitat from a major expansion of the swine farming industry (pigs served as an amplifying host; Epstein et al. 2006). Most of the diseases newly discovered in bats (Table 3 ) that have caused spill-overs fatal to humans have been in tropical or subtropical species. As the global climate warms, it is possible that more diseases enzootic in bat populations of the tropics and subtropics will move northward into the USA, with potential consequences for bat populations and human health. Disease transmission cycles are governed in part by the proportion of time each year that animals are active and interacting with each other (Dobson \& Hudson 1995), and there is evidence that torpor suspends the progression of viral diseases in bats (though this notion has received perplexingly little recent attention; La Motte 1958, Sadler \& Enright 1959, Sulkin et al. 1960). Thus, climate warming has the potential not only to move diseases into the USA and increase the length of time during the year when bats are in active contact with each other, but also to decrease any dampening effect torpor might have on disease expression and transmission. Anthropogenic changes in landscape use may also increase the probability of disease spill-over from bats in the USA, such as bat fatalities at wind turbines being scavenged by carnivores, or human encroachment into natural areas where they are more likely to come in contact with bats.

\section{Collaborative approaches to conservation and disease}

Research into diseases in bats will undoubtedly progress rapidly during the coming years. Without better knowledge of diseases that occur in bats, it will be extremely difficult to predict when and where problems are most likely to occur and thereby to respond to disease-related problems in time to avoid consequences for bat and human populations. We strongly advocate collaborative approaches to the study of disease in bats, wherein bat researchers lend their considerable expertise in the ecology and conservation of bats to virologists interested in understanding disease cycles in bats and preventing transmission to humans. Disease specialists and virologists have argued for expanded natural history surveys and protection of bat habitat from human encroachment (activities frequently advocated by bat conservationists) as means of documenting origins and preventing spill-overs of disease, respectively (Dobson 2005, Calisher et al. 2006). Although their goals may differ somewhat from those of virologists, bat biologists should embrace opportunities to participate in such work and to help craft recommendations that protect bats, their habitats, and human health.

\section{OTHER ISSUES FOR BAT RESEARCH AND CONSERVATION}

A number of related concerns for bat research and conservation in the USA are likely to rise in importance during this century. A dramatic increase in the number 
and scope of wind-energy facilities across the USA has already led to unprecedented numbers of bat fatalities, the majority of which involve inconspicuous migratory species that are killed during important migration and mating periods (Kunz et al. 2007, Arnett et al. 2008, Cryan 2008). The issues surrounding bats and wind energy reinforce several of our previous points regarding lack of existing information on inconspicuous species and their behavior outside the summer maternity season. Further, it highlights the need for speculation into issues that may become important for bats during the 21st century, so that we may better prepare ourselves for the challenges that lie ahead.

\section{Modern environmental contaminants}

Threats from modern environmental contaminants on bat populations in the USA, particularly newer generations of insecticides, are virtually unstudied, even though past contaminants have long been known to cause mortality of nursing juvenile bats and deaths of juveniles and adults during hibernation and migration (including endangered species). Recent reviews of the literature on bats and contaminants (Clark \& Shore 2001, O'Shea \& Johnston in press) documented 42 such studies published in the $20 \mathrm{yr}$ period from 1970 to 1989 , dropping to 23 in the $18 \mathrm{yr}$ period from 1990 to 2007 , and to just 1 published in the last 5 yr. Results of the most recent controlled experiments on the effects of contaminants on bats in the USA were published $>20 \mathrm{yr}$ ago. Since that time 100s and perhaps 1000s of new potential chemical threats have emerged, but unlike other facets of conservation-oriented research on bats, the study of contaminant impacts seems to have become unfashionable.

The impacts of contaminants that were the subject of earlier research were relatively easy to document. Organochlorine compounds, in particular, were persistent and lipophilic; they accumulated in tissues and had modes of action that killed bats when threshold concentrations were reached in the brain. This probably involved many days of cumulative exposure through food chains, and death often occurred while bats were at roosts (Clark \& Shore 2001, O'Shea \& Johnston in press). Thus, carcasses of affected bats could be located relatively easily by investigators, and concentrations in brains could be interpreted against results of experimental exposure studies in bats, other mammals, or birds (Peterle 1991). Impacts from newer insecticides will be more difficult to detect. This is because they do not accumulate in tissues, and effects are most likely to occur immediately upon exposure, i.e. when bats are away from the roost and foraging in areas where chemicals have been newly applied.
Cholinesterase-inhibiting organophosphate and carbamate compounds can cause lengthy sublethal incapacitation to bats immediately on exposure even if they do not kill them directly (Clark 1986, Clark \& Rattner 1987). It is easy to envision scenarios where foraging bats might become incapacitated and fall to the ground and die from exposure or predation in sprayed areas far from roosts. Such mortality would likely remain unseen by biologists. Additionally, organophosphate and carbamate pesticide exposure is known to induce hypothermia in other mammals and birds (Grue et al. 1997), an effect that in bats could have unknown but diffuse consequences (i.e. through alteration of torpor or migration and associated impacts on survival or reproductive success).

\section{Monitoring population status}

Development of methods and analytical procedures to quantitatively assess status of bat populations in the USA is a continuing conservation need. Accurate and precise estimation of trends in abundance may be impossible to accomplish for any species of US bat across its entire range, but may be more feasible in limited areas (e.g. to evaluate population response to a particular management action). In cases where abundance estimation may not be practical (O'Shea \& Bogan 2003), development of demographic models based on mark-recapture or similar estimates of key life-history parameters may be feasible and provide useful indicators of trends (e.g. Frick et al. 2007). Such approaches have been shown to be effective for ascertaining vulnerable phases in the population dynamics of other long-lived endangered vertebrates for which abundance estimation is difficult (Eberhardt 2002). New applications of site occupancy modeling to assess changes in habitat use based on presence-absence monitoring is yet another sampling tool that may become more widely applied for purposes of management and conservation of bats (MacKenzie et al. 2006, Weller 2007, 2008, Gorresen et al. 2008).

\section{Legal protection measures}

Finally, we suggest deeper thought be given to legal protection measures and conservation policies afforded to bats in the USA. Currently bats are unprotected at a national level unless they become threatened or endangered, and such protection applies to only 1 species at a time after they have suffered extraordinary threats and declines. Protection at the level of individual states varies. It may be time to move beyond 
the species-by-species approach to conservation and begin launching efforts to protect vulnerable groups of bats, or US bat species as a whole. For example, only 2 species that undertake long-distance migration (Leptonycteris spp.) are legally protected by US law; and migratory tree bats, currently experiencing continental-scale impacts at wind turbines (Kunz et al. 2007, Arnett et al. 2008), are not legally protected in any way. Like migratory birds, some bats in the USA move across state and international boundaries and can provide valuable ecological services in the form of pollination and insect pest control (Fleming et al. 1993, Cleveland et al. 2006). Threats associated with climate change, disease, or contaminants, such as the enigmatic white nose syndrome that recently began decimating colonies of bats in the northeastern USA (Veilleux 2008), may necessitate consideration of blanket protection for hibernating bats. About 30 of the 45 bat species that occur in the USA rely on cold hibernation sites for successful overwinter survival. Considering the unique survival strategies of hibernating bats (e.g. reliance on geographically limited wintering sites where both sexes interact during periods of limited food availability), previous conservation paradigms that targeted a subset of species and geographic regions might not be wholly adequate. Formal legislation or treaties for the protection of these vulnerable hibernators and transboundary migrants could be modeled after the US Marine Mammal Protection Act, the Migratory Bird Treaty Act, the United Kingdom's Wildlife and Countryside Act, or the Convention on Migratory Species of Wild Animals (O'Shea \& Bogan 2003).

\section{CONCLUSIONS}

Owing to substantial progress on the most pressing threats to bat conservation in the USA (e.g. protection of largest hibernacula), we are now in a position to expand the scope of conservation to address a broader suite of issues facing bats-problems that may be more difficult to identify and combat, but no less menacing to bat populations. Specifically, we argue for research and conservation actions aimed at inconspicuous as well as conspicuous species, that address the needs of males, reproductive females, and juveniles separately, and which account for the needs of bats during all seasons of the year. We suggest an increase in research that focuses on understanding the ecological underpinnings (e.g. thermoregulation, reproduction) of bat behavior, not only to provide explanations for current patterns of distribution and habitat selection, but also because it is likely to provide important clues that help address emerging threats (e.g. climate change, disease, and contaminants) that may impact bat populations during the 21st century. Broadening our focus to address differential responses by a wider range of species and demographic groups to a growing list of existing and emerging threats will not only produce a more holistic approach to bat conservation in the USA, but could also provide a model for other geographic regions that are ready to expand conservation efforts beyond the most immediate threats.

Acknowledgements. An invitation from F. Bonaccorso to present this paper in Merida inspired our collaborative thinking on this topic. J. Boyles, D. Krusac, W. Zielinski, and an anonymous reviewer provided helpful reviews of earlier versions of this manuscript. The USDA Forest Service International Programs supported T.J.W.'s participation in the XIV International Bat Research Conference.

\section{LITERATURE CITED}

Altringham JD, Senior P (2005) Social systems and ecology of bats. In: Ruckstuhl KE, Neuhaus P (eds) Sexual segregation in vertebrates: ecology of the two sexes. Cambridge University Press, New York, p 280-302

Arnett EB, Brown WK, Erickson WP, Fiedler JK and others (2008) Patterns of bat fatalities at wind energy facilities in North America. J Wildl Manag 72:61-78

Baker JK (1962) Notes on the Myotis of the Carlsbad Caverns. J Mammal 43:427-428

Bale JS, Masters GJ, Hodkinson ID, Awmack C and others (2002) Herbivory in global climate change research: direct effects of rising temperature on insect herbivores. Glob Change Biol 8:1-16

> Barclay RMR (1991) Population structure of temperate zone insectivorous bats in relation to foraging behaviour and energy demand. J Anim Ecol 60:165-178

Barclay RMR, Kurta A (2007) Ecology and behavior of bats roosting in tree cavities and under bark. In: Lacki MJ, Hayes JP, Kurta A (eds) Bats in forests: conservation and management. Johns Hopkins University Press, Baltimore, MD, p 17-59

Barclay RMR, Ulmer J, MacKenzie CJA, Thompson MS and others (2004) Variation in the reproductive rate of bats. Can J Zool 82:688-693

Bogan M, O'Shea TJ, Ellison L (1996) Diversity and conservation of bats in North America. Endang Species Update 13:1-13

Bogan MA, Cryan PM, Valdez EW, Ellison LE, O'Shea TJ (2003) Western crevice and cavity-roosting bats. In: O'Shea TJ, Bogan MA (eds) Monitoring trends in bat populations of the United States and teritories: problems and prospects. Information and Technology Report, USGS/ BRD/ITR-2003-0003, Biological Resources Discipline, U.S. Geological Survey, Reston, VA, p 69-77

Both C, Bouwhuis S, Lessells CM, Visser ME (2006) Climate change and population declines in a long-distance migratory bird. Nature 441:81-83

Boyles JG (2007) Describing roosts used by forest bats: the importance of microclimate. Acta Chiropt 9:297-303

Boyles JG, Robbins LW (2006) Characteristics of summer and winter roost trees used by evening bats (Nycticeius humeralis) in southwestern Missouri. Am Midl Nat 155: 210-220 
Boyles JG, Storm JJ (2007) The perils of picky eating: dietary breadth is related to extinction risk in insectivorous bats. PloS ONE 2(7):e.672

Boyles JG, Dunbar MB, Whitaker JO (2006) Activity following arousal in winter by North American vespertilionid bats. Mammal Rev 36:267-280

Boyles JG, Dunbar MB, Storm JJ, Brack V Jr (2007) Energy availability influences microclimate selection in hibernating bats. J Exp Biol 210:4345-4350

Brigham RM (2007) Bats in forests: what we know and what we need to learn. In: Lacki MJ, Hayes JP, Kurta A (eds) Bats in forests: conservation and management. Johns Hopkins University Press, Baltimore, MD, p 1-18

Brigham RM, Barclay RMR (1996) Bats and forests. In: Barclay RMR, Brigham RM (eds) Bats and forests symposium. Working Paper 23/1996, Research Branch, British Columbia Ministry of Forestry, Victoria, BC, p xi-xiv

Broders HG, Forbes GJ (2004) Interspecific and intersexual variation in roost site selection of northern long-eared and little brown bats in the Greater Fundy National Park Ecosystem, New Brunswick. J Wildl Manag 68:602-610

Broders HG, Forbes GJ, Woodley S, Thompson ID (2006) Range extent and stand selection for roosting and foraging in forest-dwelling northern long-eared bats and little brown bats in the Greater Fundy Ecosystem, New Brunswick. J Wildl Manag 70:1174-1184

Calisher CH, Childs JE, Field HE, Holmes KV, Schountz T (2006) Bats: important reservoir hosts of emerging viruses. Clin Microbiol Rev 19:531-545

Calisher CH, Holmes KV, Dominguez SR, Shountz T, Cryan PM (2008) Bats prove to be rich reservoirs for emerging viruses. Microbe 3:521-528

Childs JE, Mackenzie JS, Richt JA (2007) Wildlife and emerging zoonotic diseases: the biology, circumstances and consequences of cross-species transmission. Springer, Berlin

Christensen JH, Hewitson B, Busuioc A, Chen A and others (2007) Regional climate projections. In: Solomon S, Quin $\mathrm{D}$, Manning $\mathrm{M}$, Chen $\mathrm{Z}$ and others (eds) Climate change 2007: the physical science basis. Contribution of Working Group I to the 4th assessment report of the Intergovernmental Panel on Climate Change. Cambridge University Press, Cambridge, p 847-940

Clark DR Jr (1986) Toxicity of methyl parathion to bats: mortality and coordination loss. Environ Toxicol Chem 5: 191-195

> Clark DR Jr, Rattner BA (1987) Orthene toxicity to little brown bats (Myotis lucifugus): acetylcholinesterase inhibition, coordination loss, and mortality. Environ Toxicol Chem 6: 705-708

Clark DR Jr, Shore RF (2001) Chiroptera. In: Shore RF, Rattner BA (eds) Ecotoxicology of wild mammals. John Wiley \& Sons, London, p 159-214

> Cleveland CJ, Betke M, Federico P, Frank JD and others (2006) Economic value of the pest control service provided by Brazilian free-tailed bats in south-central Texas. Front Ecol Environ 4:238-243

Crichton EG, Krutzsch PH (eds) (2003) Reproductive biology of bats. Academic Press, New York

Cryan PM (2003) Seasonal distribution of migratory tree bats (Lasiurus and Lasionycteris) in North America. J Mammal 84:579-593

Cryan PM (2008) Mating behavior as a possible cause of bat fatalities at wind turbines. J Wildl Manag 72:845-849

Cryan PM, Veilleux JP (2007) Migration and use of autumn, winter, and spring roosts by forest bats. In: Lacki MJ, Hayes JP, Kurta A (eds) Bats in forests: conservation and management. Johns Hopkins University Press, Baltimore, MD, p 153-175
Cryan PM, Wolf BO (2003) Sex differences in the thermoregulation and evaporative water loss of a heterothermic bat, Lasiurus cinereus, during its spring migration. J Exp Biol 206:3381-3390

> Cryan PM, Bogan MA, Altenbach JS (2000) Effect of elevation on distribution of female bats in the Black Hills, South Dakota. J Mammal 81:719-725

Cryan PM, Bogan MA, Yanega GM (2001) Roosting habits of four bat species in the Black Hills of South Dakota. Acta Chiropt 3:43-52

> DeBlase AF, Humphrey SR, Drury KS (1965) Cave flooding and mortality in bats in Wind Cave, Kentucky. J Mammal 46:96

De Serres G, Dallaire F, Côte M, Skowronski DM (2008) Bat rabies in the United States and Canada from 1950 through 2007: human cases with and without bat contact. Clin Infect Dis 46:1329-1337

Dietz M, Kalko KV (2006) Seasonal changes in daily torpor patterns of free-ranging female and male Daubenton's bats (Myotis daubentonii). J Comp Physiol [B] 76:223-231

- Dobson AP (2005) What links bats to emerging infectious diseases? Science 310:628-629

Dobson AP, Hudson PJ (1995) Microparasites: observed patterns in wild animal populations. In: Grenfell BT, Dobson AP (eds) Ecology of infectious diseases in natural populations. Cambridge University Press, Cambridge, p 52-89

> Dominguez SR, O'Shea TJ, Oko LM, Holmes KV (2007) Detection of group 1 coronaviruses in bats in North America. Emerg Infect Dis 13:1295-1300

> Duchamp JE, Swihart RK (2008) Shifts in bat community structure related to evolved traits and features of humanaltered landscapes. Landscape Ecol 23:849-860

Eberhardt LL (2002) A paradigm for population analysis of long-lived vertebrates. Ecology 83:2841-2854

Ellison LE, O'Shea TJ, Bogan MA, Everette AL, Schneider DM (2003) Existing data on colonies of bats in the United States: summary and analysis of the U.S. Geological Survey's bat population database. In: O'Shea TJ, Bogan MA (eds) Monitoring trends in bat populations of the United States and territories: problems and prospects. Information and Technology Report, USGS/BRD/ITR-2003-0003, Biological Resources Discipline, U.S. Geological Survey, Roston, VA, p 127-237

Ellison LE, O'Shea TJ, Neubaum DJ, Bowen RA (2007) Factors influencing movement probabilities of big brown bats (Eptesicus fuscus) in buildings. Ecol Appl 17:620-627

> Encarnação JA, Kierdorf U, Holweg D, Jasnoch U, Wolters V (2005) Sex-related differences in roost-site selection by Daubenton's bats Myotis daubentonii during the nursery period. Mammal Rev 35:285-294

Encarnação JA, Kierdorf U, Wolters V (2007) Do mating roosts of Daubenton's bats (Myotis daubentonii) exist at summer sites? Myotis 43:31-38

Epstein JH, Field HE, Luby S, Pulliam JRC, Daszak P (2006) Nipah virus: impact, origins and causes of emergence. Curr Infect Dis Rep 8:59-65

Estók P (2007) Seasonal changes in the sex ratio of Nyctalus species in north-east Hungary. Acta Zool Acad Sci Hung 53:89-95

Fenton MB, Davison M, Kunz TH, McCracken GF, Racey PA, Tuttle MD (2006) Linking bats to emerging diseases. Science 311:1098-1099

Findley JS, Jones C (1964) Seasonal distribution of the hoary bat. J Mammal 45:461-470

Fleming TH, Eby P (2003) Ecology of bat migration. In: Kunz TH, Fenton MB (eds) Bat ecology. University of Chicago Press, Chicago, IL, p 156-208 
Fleming TH, Nuñez RA, da Silveira L, Sternberg L (1993) Seasonal changes in the diets of migrant and non-migrant nectarivorous bats as revealed by carbon stable isotope analyis. Oecologia 94:72-75

Ford WM, Owen SF, Edwards JW, Rodrigue JL (2006) Robinia pseudoacacia (black locust) as day-roosts of male Myotis septentrionalis (northern bats) on the Fernow Experimental Forest, West Virginia. Northeast Nat 13:15-24

Frick WF, Rainey WE, Pierson ED (2007) Potential effects of environmental contamination on Yuma myotis demography and population growth. Ecol Appl 17:1213-1222

Furmankiewicz J, Altringham J (2007) Genetic structure in a swarming brown long-eared bat (Plecotus auritus) population: evidence for mating at swarming sites. Conserv Genet 8:913-923

> Geluso K (2007) Winter activity of bats over water and along flyways in New Mexico. Southwest Nat 52:482-492

> Genoud M (1993) Temperature regulation in subtropical tree bats. Comp Biochem Physiol A 104:321-331

Gore JA, Hovis JA (1994) Southeastern Myotis maternity cave survey. Final performance report, Nongame Wildlife Program, Game and Fresh Water Fish Commission, Tallahassee, FL

Gorresen A, Miles AC, Todd CM, Bonaccorso FJ, Weller TJ (2008) Assessing bat detectability and occupancy with multiple automated echolocation detectors. J Mammal 89: $11-17$

Griffin DR (1945) Travels of banded cave bats. J Mammal 26:15-23

- Grindal SD, Collard TS, Brigham RM, Barclay RMR (1992) The influence of precipitation on reproduction by Myotis bats in British Columbia. Am Midl Nat 128:339-344

Grindal SD, Morissette JL, Brigham RM (1999) Concentration of bat activity in riparian habitats over an elevational gradient. Can J Zool 77:972-977

Grinevitch L, Holroyd SL, Barclay RMR (1995) Sex differences in the use of daily torpor and foraging time by big brown bats (Eptesicus fuscus) during the reproductive season. J Zool (Lond) 235:301-309

Grue CE, Gilbert PL, Seeley ME (1997) Neurophysiological and behavioral changes in non-target wildlife exposed to organophosphate and carbamate pesticides: thermoregulation, food consumption, and reproduction. Am Zool 37: 369-388

> Halpin K, Young PL, Field HE, Mackenzie JS (2000) Isolation of Hendra virus from pteropid bats: a natural reservoir of Hendra virus. J Gen Virol 81:1927-1932

- Hamilton IM, Barclay RMR (1994) Patterns of daily torpor and day-roost selection by male and female big brown bats (Eptesicus fuscus). Can J Zool 72:744-749

Hamilton IM, Barclay RMR (1998) Ontogenetic influences on foraging and mass accumulation by big brown bats (Eptesicus fuscus). J Anim Ecol 67:930-940

Hayes JP (2003) Habitat ecology and conservation of bats in western coniferous forests. In: Zabel CJ, Anthony RG (eds) Mammal community dynamics in coniferous forests of western North America - management and conservation. Cambridge University Press, Cambridge, p 81-119

Henry M, Thomas DW, Vaudry R, Carrier M (2002) Foraging distances and home range of pregnant and lactating little brown bats (Myotis lucifugus). J Mammal 83: $767-774$

> Humphrey SR (1975) Nursery roosts and community diversity of Nearctic bats. J Mammal 56:321-346

Humphries MM, Thomas DW, Speakman JR (2002) Climatemediated energetic constraints on the distribution of hibernating mammals. Nature 418:313-316
Humphries MM, Thomas DW, Kramer DL (2003) The role of energy availability in mammalian hibernation: a cost benefit approach. Physiol Biochem Zool 76:165-179

Hutson AM, Mickleburgh SP, Racey PA (eds) (2001) Microchiropteran bats: global status survey and conservation action plan. IUCN/SSC Chiroptera Specialist Group, IUCN, Gland

Janies D, Habib F, Alexandrov B, Hill A, Pol D (2008) Evolution of genomes, host shifts and the geographic spread of SARS-CoV and related coronaviruses. Cladistics 23:1-20

> Jones KE, Purvis A, Gittleman JL (2003) Biological correlates of extinction risk in bats. Am Nat 161:601-614

> Jönsson KI (1997) Capital and income breeding as alternative tactics of resource use in reproduction. Oikos 78:57-66

> Kalcounis-Rüppell MC, Psyllakis J, Brigham RM (2005) Tree roost selection by bats: an empirical synthesis using metaanalysis. Wildl Soc Bull 33:1123-1132

Kokurewicz T, Speakman JR (2006) Age related variation in the energy costs of torpor in Daubenton's bat: effects on fat accumulation prior to hibernation. Acta Chiropt 8:509-521

Kunz TH, Lumsden LF (2003) Ecology of cavity and foliage roosting bats. In: Kunz TH, Fenton MB (eds) Bat ecology. University of Chicago Press, Chicago, IL, p 3-89

Kunz TH, Stern AA (1995) Maternal investment and postnatal growth in bats. Symp Zool Soc Lond 67:123-138

Kunz TH, Wrazen JA, Burnett CD (1998) Changes in body mass and fat reserves in pre-hibernating little brown bats (Myotis lucifugus). Ecoscience 5:8-31

> Kunz TH, Arnett EB, Erickson WP, Hoar AR and others (2007) Ecological impacts of wind energy development on bats: questions, research needs, and hypotheses. Front Ecol Environ 5:315-324

Kurta A (1986) Factors affecting the resting and postflight body temperature of little brown bats, Myotis lucifugus. Physiol Zool 59:429-438

Kurta A, Fujita MS (1988) Design and interpretation of laboratory thermoregulation studies. In: Kunz TH (ed) Ecological and behavioral methods for the study of bats. Smithsonian Institution Press, Washington, DC, p 333-352

Kurta A, Kunz TH (1988) Roosting metabolic rate and body temperature of male little brown bats (Myotis lucifugus) in summer. J Mammal 69:645-651

La Motte LC (1958) Japanese B Encephalitis in bats during simulated hibernation. Am J Epidemiol 67:101-108

Lausen CL, Barclay RMR (2006) Winter bat activity in the Canadian prairies. Can J Zool 84:1079-1086

> Leroy EM, Kumulungui B, Pourrut X, Rouquet P and others (2005) Fruit bats as reservoirs of Ebola virus. Nature 438:575-576

MacKenzie DI, Nichols JD, Royle JA, Pollock KH, Bailey LL, Hines JE (2006) Occupancy estimation and modeling: inferring patterns and dynamics of species occurrence. Elsevier, London

McCracken GF, Wilkinson GS (2000) Mating systems in bats. In: Crichton EG, Krutzsch PH (eds) Reproductive biology of bats. Academic Press, New York, p 321-362

Messenger SL, Rupprecht C, Smith JS (2003) Bats, emerging virus infections, and the rabies paradigm. In: Kunz TH, Fenton MB (eds) Bat ecology. University of Chicago Press, Chicago, IL, p 622-679

> Mondul AM, Krebs JW, Childs JE (2003) Trends in national surveillance for rabies among bats in the United States (1993-2000). J Am Vet Med Assoc 222:633-639

> Neubaum DJ, O'Shea TJ, Wilson KR (2006) Autumn migration and selection of rock crevices as hibernacula by big brown bats (Eptesicus fuscus) in Colorado. J Mammal 87: $470-479$ 
O'Shea TJ, Bogan MA (eds) (2003) Monitoring trends in bat populations of the United States and territories: problems and prospects. Information and Technology Report USGS/BRD/ITR-2003-0003, Biological Resources Discipline, U.S. Geological Survey, Roston, VA

O'Shea TJ, Johnston JJ (in press) Investigating impacts of environmental contaminants on bats. In: Kunz TH, Parsons $\mathrm{S}$ (eds) Ecological and behavioral methods for the study of bats. Johns Hopkins University Press, Baltimore, $\mathrm{MD}$

O'Shea TJ, Bogan MA, Ellison LE (2003) Monitoring trends in bat populations of the United States and territoriesstatus of the science and recommendations for the future. Wildl Soc Bull 31:16-29

O'Shea TJ, Ellison LE, Stanley TR (2004) Survival estimation in bats: historical overview, critical appraisal, and suggestions for new approaches. In: Thompson WL (ed) Sampling rare or elusive species: concepts, designs, and techniques for estimating population parameters. Island Press, Washington, DC, p 297-336

Pearce RD, O'Shea TJ, Shankar V, Rupprecht CE (2007) Lack of association between ectoparasite intensities and rabies virus neutralizing antibody seroprevalence in wild big brown bats (Eptesicus fuscus), Fort Collins, Colorado. Vector Borne Zoonotic Dis 7:489-495

Perry RW, Thill RE, Carter AS (2007) Sex-specific roost selection by adult red bats in a diverse forested landscape. For Ecol Manage 253:48-55

Peterle JJ (1991) Wildlife toxicology. Van Nostrand Reinhold, New York

Pierson ED (1998) Tall trees, deep holes, and scarred landscapes: conservation biology of North American bats. In: Kunz TH, Racey PA (eds) Bat biology and conservation. Smithsonian Institution Press, Washington, DC, p 309-325

Racey PA (1973) Environmental factors affecting the length of gestation in heterothermic bats. J Reprod Fertil Suppl 19:175-189

Racey PA (1982) Ecology of bat reproduction. In: Kunz TH (ed) The ecology of bats. Plenum Press, New York, p 57-104

Racey PA, Entwistle AC (2003) Conservation ecology of bats. In: Kunz TH, Fenton MB (eds) Bat ecology. University of Chicago Press, Chicago, IL, p 680-743

Ransome R (1990) The natural history of hibernating bats. Christopher Helm, London

Reynes JM, Counor D, Ong S, Faure C and others (2005) Nipah virus in Lyle's flying foxes, Cambodia. Emerg Infect Dis 11:1042-1047

Rhodes M (2007) Roost fidelity and fission-fusion dynamics of white-striped free-tailed bats (Tadarida australis). J Mammal 88:1252-1260

Rolseth SL, Koehler CE, Barclay RMR (1994) Differences in the diets of juvenile and adult hoary bats, Lasiurus cinereus. J Mammal 75:394-398

Rubin ES, Bleich VC (2005) Sexual segregation: a necessary consideration in wildlife conservation. In: Ruckstuhl KE, Neuhaus P (eds) Sexual segregation in vertebrates: ecology of the two sexes. Cambridge University Press, Cambridge, p 379-391

Sachteleben J, von Helversen O (2006) Songflight behavior and mating system of the pipistrelle bat (Pipistellus pipistrellus) in an urban habitat. Acta Chiropt 8:391-491

Sadler WW, Enright JB (1959) Effect of metabolic level of the host upon the pathogenesis of rabies in the bat. J Infect Dis 105:267-273

Safi K, Kerth G (2004) A comparative analysis of specializa- tion and extinction risk in temperate-zone bats. Conserv Biol 18:1293-1303

Safi K, König B, Kerth G (2007) Sex differences in population genetics, home range size and habitat use of the particoloured bat (Vespertilio murinus Linnaeus, 1758) in Switzerland and their consequences for conservation. Biol Conserv 137:28-36

Scatterday JE (1954) Bat rabies in Florida. J Am Vet Med Assoc 124:125

Sekercioglu CH, Schneider SH, Fay JP, Loarie SR (2008) Climate change, elevational range shifts, and bird extinctions. Conserv Biol 22:140-150

Senior P, Butlin RK, Altringham JD (2005) Sex and segregation in temperate bats. Proc R Soc Lond B Biol Sci 272: $2467-2473$

Shankar V, Bowen RA, Davis AD, Rupprecht CE, O'Shea TJ (2004) Rabies in a captive colony of big brown bats (Eptesicus fuscus). J Wildl Dis 40:403-413

Simmons NB (2005) Order Chiroptera. In: Wilson DE, Reeder DM (eds) Mammal species of the world. Johns Hopkins University Press, Baltimore, MD, p 312-529

Soulé ME (1985) What is conservation biology? Bioscience 35:727-734

Speakman JR, Thomas DW (2003) Physiological ecology and energetics of bats. In: Kunz TH, Fenton MB (eds) Bat ecology. University of Chicago Press, Chicago, IL, p 430-490

Strelkov PP (1969) Migratory and stationary bats (Chiroptera) of the European part of the Soviet Union. Acta Zool Cracov 14:393-440

Sulkin SE, Allen R, Sims R, Krutzsch PH, Kim C (1960) Studies on the pathogenesis of rabies in insectivorous bats. 2 . Influence of environmental temperature. J Exp Med 112: 595-617

Thomas DW (1988) The distribution of bats in different ages of douglas-fir forests. J Wildl Manag 52:619-626

- Towner JS, Pourrut X, Albariño CG, Nkogue CN and others (2007) Marburg virus infection detected in common African bat. PLoS One 2(8):e764

Twente JW Jr (1955) Some aspects of habitat selection and other behavior of cavern-dwelling bats. Ecology 36: 706-732

US Fish and Wildlife Service (1994) 50 CFR Part 17, endangered and threatened wildlife and plants; animal candidate review for listing as endangered or threatened species. Federal Register 59:58982-59028

Veilleux JP (2008) Current status of white-nose syndrome in the northeastern United States. Bat Res News 49:15-17

Waldien DL, Hayes JP, Arnett EB (2000) Day-roosts of female long-eared Myotis in western Oregon. J Wildl Manag 64:785-796

Weller TJ (2007) Assessing population status of bats in forests: challenges and opportunities. In: Lacki MJ, Hayes JP, Kurta A (eds) Bats in forests: conservation and management. Johns Hopkins University Press, Baltimore, MD, p 263-291

Weller TJ (2008) Using occupancy estimation to assess the effectiveness of a regional multiple-species conservation plan: bats in the Pacific Northwest. Biol Conserv 141: $2279-2289$

Weller TJ, Zabel CJ (2001) Characteristics of fringed Myotis day roosts in northern California. J Wildl Manag 65: 489-497

> Willis CKR, Brigham RM (2007) Social thermoregulation exerts more influence than microclimate on forest roost preferences by a cavity-dwelling bat. Behav Ecol Sociobiol 62:97-108

Wilson RJ, Gutiérrez D, Gutiérrez J, Martinez D and others 
(2005) Changes to the elevational limits and extent of species ranges associated with climate change. Ecol Lett 8: 1138-1146

Wojciechowski MS, Jefimow M, Tegowska E (2007) Environmental conditions, rather than season, determine torpor use and temperature selection in large mouse-eared bats (Myotis myotis). Comp Biochem Physiol 147A: 828-840

Editorial responsibility: Stephen Rossiter, London, UK
Wong S, Lau S, Woo P, Yuen KY (2007) Bats as a continuing source of emerging infections in humans. Rev Med Virol 17:67-91

Zahn A, Dippel B (1997) Male roosting habits and mating behaviour of Myotis myotis. J Zool (Lond) 243:659-674

Zimmerman FR (1937) Migration of little brown bats. J Mammal 17:363

Submitted: June 6, 2008; Accepted: September 24, 2008

Proofs received from author(s): December 25, 2008 